\title{
A Novel Methodology for Calculating Crack Opening Stress under Tension-Compression Cyclic Load
}

\author{
Lin Zhang $\mathbb{D I}^{1}$ and Xiaohui Wei $\mathbb{D}^{1,2}$ \\ ${ }^{1}$ Key Laboratory of Fundamental Science for National Defense-Advanced Design Technology of Flight Vehicle, \\ Nanjing University of Aeronautics and Astronautics, Nanjing 210016, Jiangsu, China \\ ${ }^{2}$ State Key Laboratory of Mechanics and Control of Mechanical Structures, Nanjing University of Aeronautics and Astronautics, \\ Nanjing 210016, Jiangsu, China \\ Correspondence should be addressed to Xiaohui Wei; wei_xiaohui@nuaa.edu.cn
}

Received 12 August 2021; Revised 8 November 2021; Accepted 9 November 2021; Published 7 December 2021

Academic Editor: Hiroshi Yoshihara

Copyright ( $) 2021$ Lin Zhang and Xiaohui Wei. This is an open access article distributed under the Creative Commons Attribution License, which permits unrestricted use, distribution, and reproduction in any medium, provided the original work is properly cited.

\begin{abstract}
Crack closure model has been used in several applications on the prediction of fatigue crack growth life, with expression of crack opening stress often serving as milestones. A typical difficulty in calculating the crack opening stress is the phenomenon of crack closure caused by the compressive load effect. Compressive load effect, resulting in the change of residual stress status at the unloading stage and the decrease of crack opening stress, is a long-term challenge for predicting fatigue crack growth life. We propose the expression of crack opening stress to predict fatigue crack growth life based on the analysis of compact tensile specimen with elastoplastic element method. It combines the characteristics of material and load to deal with the phenomenon of crack closure and uses stress ratio and normalized maximum applied load variable to construct the expression of crack opening stress. In the study of tensile-compression fatigue crack growth experiments, the proposed expression is proved to improve, by comparative analysis, the predictive ability on the whole range of experiment data. The novel expression is accurate and simple. Consequently, it is conducive to calculate the crack opening stress under tension-compression load.
\end{abstract}

\section{Introduction}

The fatigue crack growth is a common and important issue in engineering application, due to the inevitable defects in materials and structures [1]; and the small defect in material and structure, which is also considered as a small crack, propagates into a large one under cyclic load and results in fracture $[2,3]$. A more serious problem is that some engineering structures are subjected to both tensile and compressive loads [4-6]. For example, the landing gear of aircraft is subjected to cyclic compression load during landing process [7]. Previous studies have considered that compression load leads to crack closure; namely, compression load can delay crack growth rate and prolong crack life [8]. Based on the concept of conservative design, the effect of compression load is not considered in the calculation of fatigue crack growth life [9]. In order to improve the accuracy of life calculation for engineering structure subjected to compression load, damage tolerance and durability design are proposed, in which the calculation of fatigue crack growth rate is one of the key contents $[10,11]$. Due to the fact that the effective driving force directly reflects the fatigue crack growth rate, it is necessary to establish an effective driving force model for crack growth [12-14].

Since Elber put forward the concept of crack closure, many efforts have been devoted to calculating the effective driving force based on the mechanism of crack closure [15-17]. Among them, the plastic-induced crack closure mechanism is widely used to calculate the effective driving force of crack growth [18]. Based on the mechanism of crack closure caused by plasticity, the expression of crack opening stress is the basis of calculating effective driving force. Due to the large stress gradient near the crack tip, the analytical solution of the crack opening stress cannot be obtained by 
fracture mechanics, and the experiment method needs a large number of samples for statistical analysis [19]. Therefore, the numerical method is widely used to calculate the crack opening stress [20]. At present, there are four numerical methods to evaluate crack opening and closing [21], that is, the displacement of the first node behind the crack tip, the displacement of the second node behind the crack tip, the stress transformation of the crack tip, and the weight function method based on contact stress along the crack surface. The nodal displacement method is the first method to calculate the opening and closing stresses. It includes monitoring the displacement of node (usually the first or second node behind the crack tip) when cyclic load is applied. Later, the concept of stress change at the crack tip was proposed to analyze the phenomenon of crack closure. Then, when the stress at the crack tip node changes from compression to tension, the externally applied stress is defined as the crack opening stress. On this basis, it is proposed that the opening stress is defined as the applied stress when the stress perpendicular to the crack plane at the crack tip node changes from compression to tension. For the weight function method to calculate the opening stress, the residual stress on crack surface is used to calculate the (negative) residual stress intensity factor $[22,23]$. The negative residual stress intensity factor itself has no physical meaning, but it can be used to calculate the crack opening stress by the opening stress intensity. Due to the existence of plasticity in the unloading part of cyclic loading, the elastic superposition is no longer effective, so the weight function method cannot be used to calculate the crack opening stress under the circumstance of compressive load [24]. Therefore, when discussing the crack opening stress under tensioncompression cyclic loading, the crack opening stress is often calculated based on the transformation of stress and displacement.

Compression load is an important factor affecting the opening stress [25]. Based on the mechanism of crack closure, Schijve, Koning, Newman, and Lang proposed some empirical formulas for calculating the crack opening stress, where the stress ratio, maximum stress intensity factor, and residual stress were taken as control parameters. Later, a twoparameter model with the combination of stress intensity factor amplitude, maximum applied load, crack tip opening displacement, and crack tip constraint condition was proposed $[26,27]$. Most of the primary crack opening stress formulas were limited to stress ratio of single-parameter model and crack opening displacement of two-parameter model. When the peak and valley values of tension-compression cyclic loads are large, the calculation ability of these crack opening stress formulas decreases. There are two main reasons for the decline of computing power. One reason is that the opening stress model based on the positive stress ratio of cyclic tensile load is not suitable for the negative stress ratio of tensile-compression cyclic load [28]. Another reason is that the plastic-induced crack closure is related to not only the load characteristics but also the material characteristics [29]. For these reasons, many efforts have been made to establish an effective expression to predict the crack opening stress under tension-compression cyclic load.
In this work, a novel methodology is proposed to calculate crack opening stress based on the mechanism of plastic-induced crack closure, considering the effect of compressive load. The proposed crack opening stress model is applicable to predict fatigue crack life under cyclic loading. In order to verify the applicability of the proposed crack opening stress model, the crack growth experiment data of CT specimen are quoted, and the elastoplastic finite element model is established. Through the elastoplastic finite element analysis of the CT specimen, the effects of maximum load, stress ratio, and yield stress on crack opening stress are investigated; and the explicit expression is established for the calculation of crack opening stress. Besides, the proposed model is used to predict the fatigue crack life of CT specimen. Compared with the result of experiment and literature, it is shown that the crack opening stress model can be applied to predict the fatigue crack life under cyclic loading [30]. Therefore, we succeed in predicting fatigue crack life with the proposed crack opening stress model and improving the accuracy of predicting effective stress amplitude.

\section{Methodology}

2.1. Theoretical Considerations. The essence of residual stress near crack tip is the plastic behavior of material, and the plastic behavior of materials is induced by the applied load [31]. The plastic behavior of materials can be expressed by elastic modulus, yield stress, and strain hardening; also the applied load can be expressed by peak value, valley value, and stress ratio. The purpose of analyzing plastic closure behavior is to calculate crack opening stress, which changes the effective stress amplitude, and the crack opening stress is a key factor for the prediction of crack growth life. In this work, the crack surface is assumed to be completely open, when the node stress of crack tip changes from compressive stress to tensile stress. Accordingly, when the crack tip stress is zero, the applied load is defined as the crack opening stress, that is, crack opening stress.

According to the literatures, stress ratio, maximum load, and yield stress have great influence on the crack opening stress $[32,33]$. For the plastic crack closure under cyclic loading, it is also considered that the effect of compressive load on crack opening stress cannot be ignored. Therefore, the stress ratio, peak value, and valley value are selected to reflect the influence of load characteristics on crack opening stress, and the yield stress and hardening effect are selected to reflect the influence of material characteristics on crack opening stress. The relationship between crack opening stress and these factors can be expressed as

$$
\sigma_{o p} \sim f(\text { Mat, Load), }
$$

where Mat $\sim g\left(\sigma_{s}, n\right)$ and Load $\sim h\left(R, \sigma_{\max }, \sigma_{\text {com }}\right)$.

For cyclic loading, the load characteristics can be expressed by any combination of two factors: stress ratio, peak load, valley load, average stress, and stress amplitude. For the purpose of convenient calculation, the stress ratio, peak load, and compressive load are chosen to find an effective expression for calculating crack opening stress. 
2.2. Finite Element Analysis. The calculation code of the elastoplastic finite element for CT specimen is coded by APDL language of ANSYS 16.2. The geometric dimension of CT specimen is established according to ASTM-E399, as shown in Figure 1; and the width of specimen is chosen as reference size; $W=76 \mathrm{~mm}$.

An elastic-perfectly plastic model is given to the material of steel, where the modulus of elasticity is $200 \mathrm{GPa}$, the yield stress is $300 \mathrm{MPa}$, and Poisson's ratio is 0.3 . The eight-node quadrilateral element (PLANE 183) is used to establish the two-dimensional finite element model. Moreover, nodes to rigid line contact pair are established on the crack surface and notch boundary to prevent the crack from penetrating, namely, the negative displacement of nodes on crack surface [34]. The parameters of contact pairs are obtained from trial calculation with the command of CNCHECK, so as to improve the contact parameters in the final model. Considering the symmetry of geometry and load, a half of CT structure is meshed, as shown in Figure 2.

The finite element model is meshed with the method of increasing refinement, which can reflect the large stress gradient near the crack tip and also can control the scale of finite element model [35]. Firstly, the Irwin plastic zone model of equation (2) is used to estimate the size of plastic zone; then the transition zone of mesh size is established to obtain the refined mesh. Since half of the CT specimen is used, a symmetrical constraint is applied on the plane of symmetry as shown in Figure 3, where the loading force is applied to the loading hole, according to ASTM-E399. Additionally, fixed constraints are applied on the rigid line to prevent the penetration behavior of crack and notch zone.

$$
r_{p}=\beta\left(\frac{K}{\sigma_{y}}\right)^{2} \begin{cases}\beta=\frac{1}{2 \pi} & \text { for plane stress } \\ \beta=\frac{1}{6 \pi} & \text { for plane strain }\end{cases}
$$

The criterion of crack opening is mainly based on the stress and displacement state of the crack tip node in numerical analysis [36], namely, the first node behind the crack tip, the second node behind the crack tip, and the contact nodes of the crack surface, as shown in Figure 4. Among them, the stress state of crack tip node is widely used as the criterion of crack opening. The displacement of the first node behind the crack tip has also been used to evaluate the crack opening state [37]. Considering the premature closure of the first node behind the crack tip, the displacement of the second node behind the crack tip has been used to evaluate the crack opening state. Considering that the node state on crack surface depends on the subdivision degree of the mesh, the contact stress of crack surface is used to calculate the crack opening stress. In this paper, the crack opening stress is calculated with the linear interpolation method by monitoring the stress state of crack tip node.

The convergence analysis of the finite element model is conducted under the loading condition of $R=0$ and $P_{\max }=80 \mathrm{MPa}$. According to the method of increasing refinement, the number of nodes in the plastic zone is

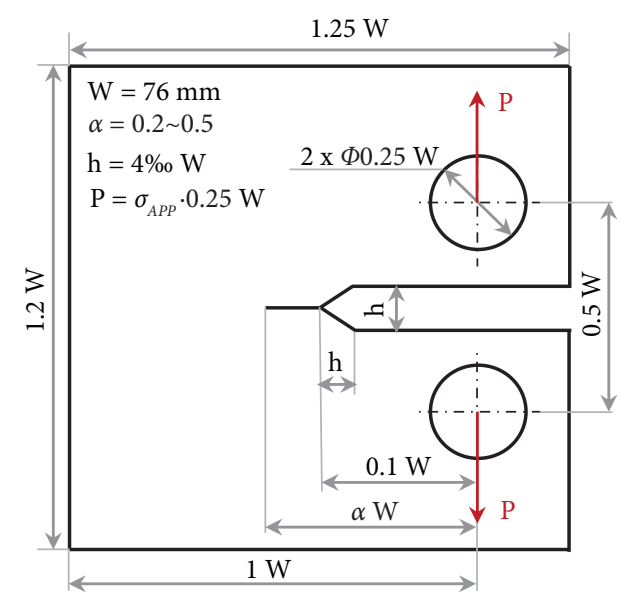

FIGURE 1: The geometric dimension of CT specimen. The specimen is established according to ASTM-E399, in which $W$ is taken as reference size. The crack length is in the range of 0.2 to 0.5 times of $W$. The loading force is transformed into the applied pressure according to the size of the loading hole.

increased from 5 to 30 , and the incremental Step 5 is used to study the mesh convergence. When the number of nodes in the plastic zone is greater than 20 , the numerical results have no obvious change. Therefore, there are 20 nodes in the plastic zone at the crack tip, and the minimum element size is $0.6 \mu \mathrm{m}$. Consequently, the refined finite element model of the half CT specimen has 78000 elements and 87000 nodes. Further reducing the element size will increase the calculation time. Meanwhile, according to McClung and Sehitoglu, the minimum element size of crack tip in finite element simulation should be one twentieth of the size of plastic zone [38]. Therefore, it is appropriate to arrange 20 nodes in the plastic zone.

\section{Results}

3.1. Correlation between Opening Stress and Stress Ratio. The stress ratio and the maximum tensile load are selected as variables, and the opening stress is calculated by the established elastic-plastic finite element model. The maximum tensile load is between 80 and $240 \mathrm{MPa}$ with equal interval of $40 \mathrm{MPa}$, and the stress ratio is changed from 0 to -0.5 with equal interval of 0.1 . In order to compare the opening stress under different maximum tensile loads, the corresponding opening stress is normalized by the maximum tensile load, and the obtained opening stress curve is shown in Figure 5.

The numerical results are shown in Figure 5 with the form of data points. It can be seen that the level of crack opening stress decreases with the increase of the maximum tensile load. Besides, the crack opening stress levels decrease with the increase of negative stress ratio, under five different levels of maximum tensile load. Namely, the compression load can reduce the crack opening stress. Moreover, the crack opening stress is negative when the maximum tensile load is greater than $160 \mathrm{MPa}$ and the negative stress ratio is greater than 0.3. The crack opening stress curves under five levels of maximum tensile loads show the characteristics of quadratic trinomial with respect to stress ratio. Therefore, 


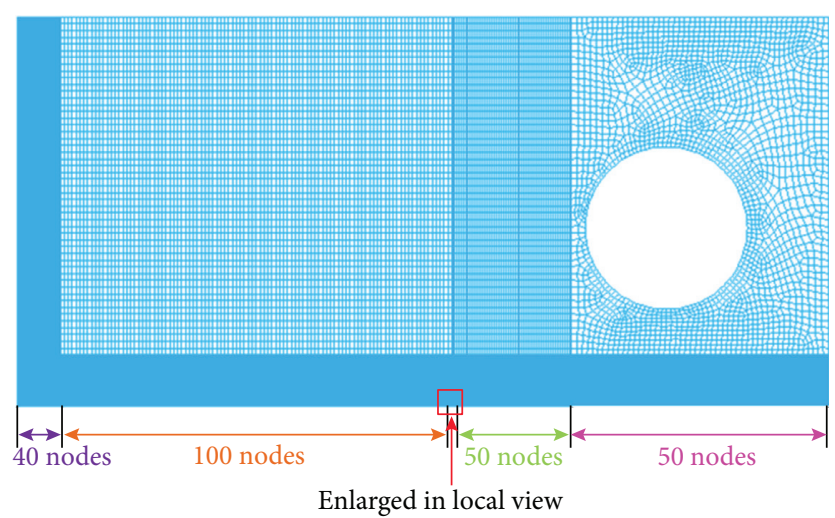

(a)

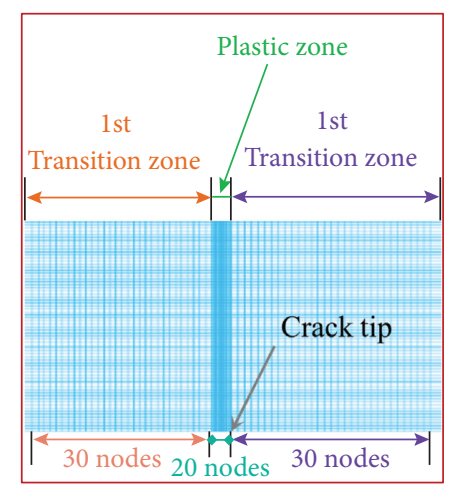

(b)

Figure 2: The finite element model of CT specimen. According to the size of plastic zone, the specimen is divided into seven intervals along the length direction. Based on the benchmark node of crack tip, 20 nodes are arranged in the plastic zone before crack tip node, and 30 nodes are arranged in the adjacent transition zone, as shown in the enlarged local view. In the rest of four intervals, the number of nodes per unit length is gradually reduced. (a) Global mesh dimensions; (b) local mesh dimensions.

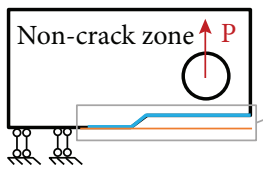

(a) Half of CT

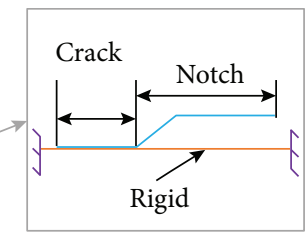

(b) Enlarged of crack zone
FIGURE 3: Schematic of boundary and constraint. (a) Due to the symmetry of structure, it is necessary to impose symmetrical constraints on the symmetrical plane. (b) To prevent the crack surface from penetrating, a contact pair is established with the crack and notch through the rigid line; therefore, it is necessary to impose fixed constraints on the rigid line.
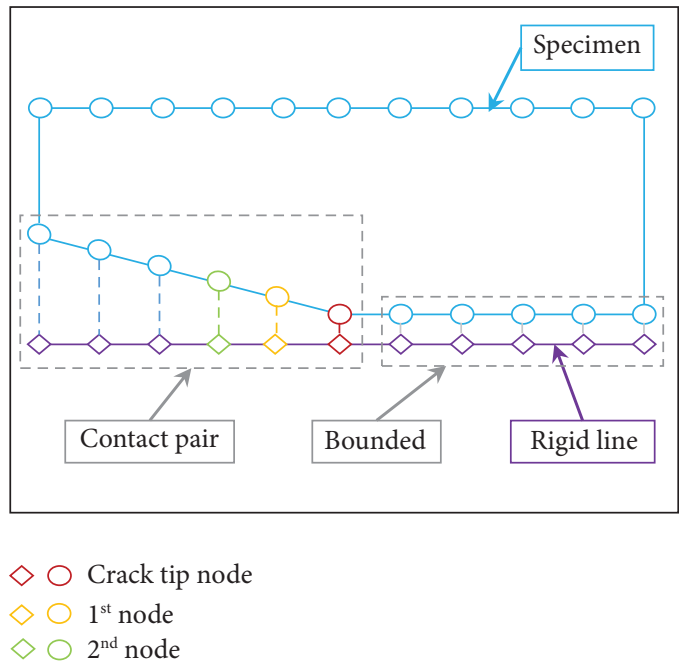

FIGURE 4: The criterion of crack opening stress. The difference of crack opening stress criterion lies in monitoring different nodes on the crack surface. The CT specimen is shown in the form of line with dots, and the nodes monitored by different criteria are distinguished by node color.

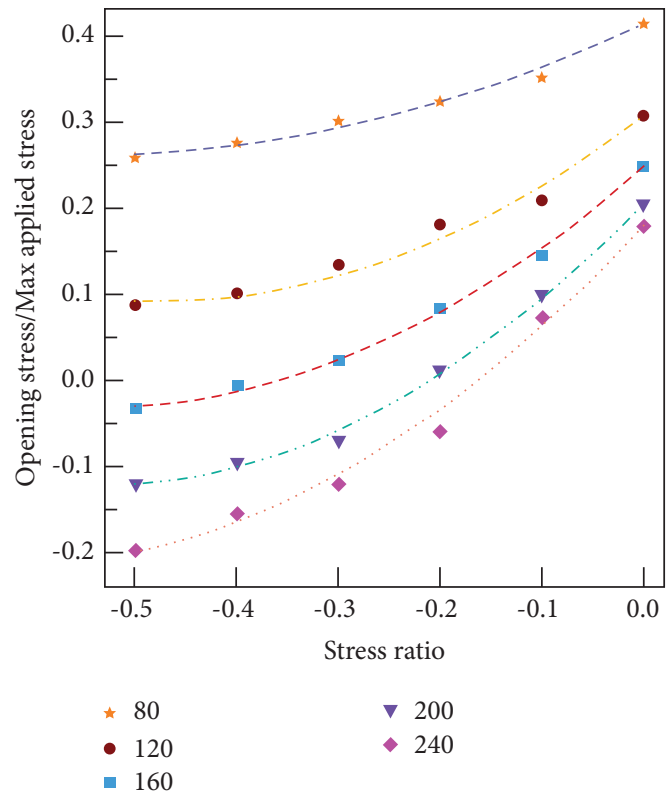

FIGURE 5: Opening stress curve. With the same amplitude of maximum load, the opening stress decreases with the increase of compressive load (i.e., the increase of negative stress ratio). The decrease of opening stress can be described by quadratic polynomial of stress ratio, as shown by five types of dashed line. When the maximum load is greater than $160 \mathrm{MPa}$, the opening stress will be negative with the increase of compressive load. It means that the crack opens during the unloading stage of compressive load. It means that the crack opens during the unloading stage of compressive load.

the following quadratic trinomial is used to fit the crack opening stress curves under different maximum loads:

$$
\frac{\sigma_{o p}}{\sigma_{\max }}=\frac{\sigma_{o p \_} 0}{\sigma_{\max }}+b_{1} R+b_{2} R^{2} .
$$

We have that $\sigma_{o p_{-} 0}$ is the crack opening stress when the stress ratio is zero. The coefficients of fitting expression for 
crack opening stress curve under each maximum tensile load are given in Table 1.

The fitting coefficients of quadratic trinomial in the table are obtained under the condition that the determination coefficient and correction determination coefficient are greater than 0.98 , which indicates that the fitting effect is good. Furthermore, by comparing the reduction rate of crack opening stress with stress ratio under five kinds of maximum tensile loads, it is found that the reduction rate is positively related to the maximum tensile load. Therefore, it is necessary to analyze the influence of maximum tensile load on crack opening stress.

3.2. The Effect of Maximum Tensile Load. To analyze the effect of the maximum tensile load, the fitting value of the variables in equation (3) with the change of the normalized maximum tensile load is plotted in Figure 6.

It can be seen that both the first degree and the second degree $b_{2}$ in equation (3) are positively correlated with the normalized maximum tensile load and show exponential variation; and the intercept $\sigma_{o p_{-} 0} / \sigma_{\max }$ of the polynomial is also exponential to the maximum tensile load. However, contrary to the rule that the coefficients of $b_{1}$ and $b_{2}$ increase with the increase of the maximum tensile load, the polynomial intercept $\sigma_{o p_{-} 0} / \sigma_{\max }$ decreases with the increase of the maximum tensile load. Therefore, equation (4) is used to fit the relationship between the polynomial coefficients and the normalized maximum tensile load.

$$
y=a \cdot \exp \left(\frac{d}{\sigma_{\max } / \sigma_{s}+c}\right) .
$$

We have that $\sigma_{\max } / \sigma_{s}$ is the normalized maximum tensile load normalized by yield stress. The coefficients of equation (4) are given in Table 2.

The fitting coefficients of the exponential expression in Table 2 are obtained under the condition that both the determination coefficient and the adjusted determination coefficient are greater than 0.97 , which indicates that the fitting effect is good. Considering that the variation law and numerical values of $b_{1}$ and $b_{2}$ are similar, also the coefficients of the exponential expression are close. Therefore, the average value is used to modify the expression for calculating the effect of the maximum tensile load.

$$
y=a \cdot \exp \left(\frac{-0.3215}{\sigma_{\max } / \sigma_{s}+0.0246}\right) .
$$

Therefore, $a$ is 2.2498 in the exponential relationship between $b_{1}$ and the maximum tensile load, and $a$ is 2.0764 in the exponential relationship between $b_{2}$ and the maximum tensile load. According to the fitting coefficients in Table 2, the following formula is obtained to calculate $\sigma_{o p_{-} 0} / \sigma_{\max }$ :

$$
y=a \cdot \exp \left(\frac{0.3215}{\sigma_{\max } / \sigma_{s}+0.0246}\right) .
$$

TABLE 1: Fitting coefficients of quadratic trinomial.

\begin{tabular}{lccc}
\hline$\sigma_{\max } / \sigma_{s}$ & $b_{1}$ & $b_{2}$ & $\sigma_{o p_{0} 0} / \sigma_{\max }$ \\
\hline $\mathbf{0 . 2}$ & 0.5459 & 0.4873 & 0.4125 \\
$\mathbf{0 . 3}$ & 0.8414 & 0.8132 & 0.3067 \\
$\mathbf{0 . 4}$ & 1.0320 & 0.9540 & 0.2469 \\
$\mathbf{0 . 5}$ & 1.2175 & 1.1339 & 0.2050 \\
$\mathbf{0 . 6}$ & 1.3574 & 1.2262 & 0.1792 \\
\hline
\end{tabular}

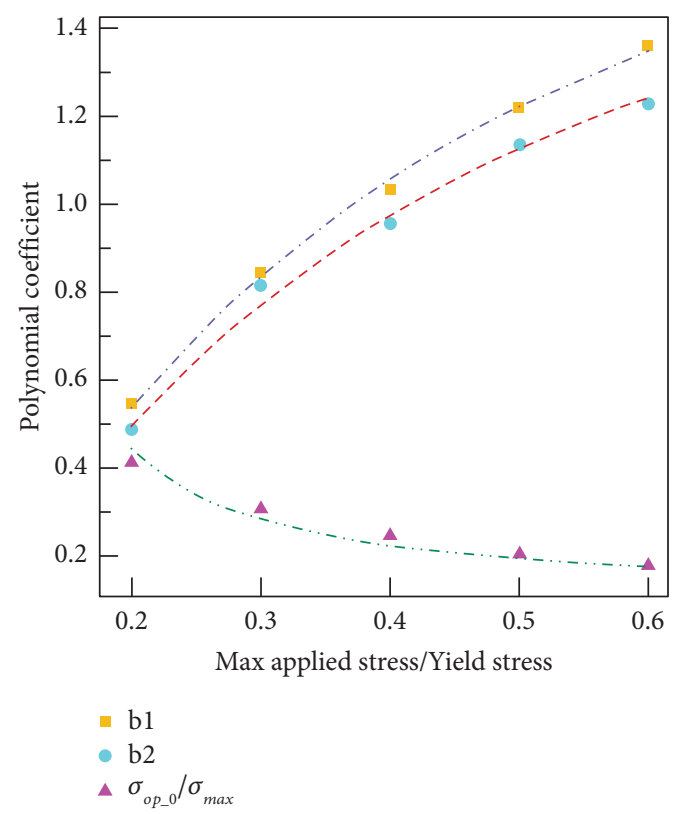

FIgURE 6: Correlation between polynomial coefficients and maximum applied stress. Both polynomial coefficients $b_{1}$ and $b_{2}$ are exponential to the maximum applied stress, as shown by the square and circular points. The polynomial intercept $\sigma_{o p_{-} 0} / \sigma_{\max }$ is also exponential to the maximum applied stress, as shown by the triangle points. However, contrary to the increasing trend of $b_{1}$ and $b_{2}, \sigma_{o p_{0} 0} / \sigma_{\max }$ showed a decreasing trend with the increase of maximum applied stress.

TABLE 2: Fitting coefficients of exponential expression.

\begin{tabular}{lccc}
\hline Coefficient & $a$ & $c$ & $d$ \\
\hline$\sigma_{o p_{\perp} 0} / \sigma_{\max }$ & 0.1058 & 0.0246 & 0.3215 \\
b1 & 2.4823 & 0.0692 & -0.4056 \\
b2 & 1.8416 & -0.0200 & -0.2373 \\
\hline
\end{tabular}

Correspondingly, the fitting coefficient $a$ for $\sigma_{o p_{-} 0} / \sigma_{\max }$ becomes 0.1058 in the modified exponential expression; and the determination coefficient and the adjusted determination coefficient are greater than 0.95 , which indicates that the fitting effect is good. To sum up, there is the following expression: 


$$
\left\{\begin{array}{l}
\sigma_{o p} / \sigma_{\max }=\sigma_{o p_{-} 0} / \sigma_{\max }+b_{1} R+b_{2} R^{2} \\
\sigma_{o p_{-} 0} / \sigma_{\max }=0.1058 \exp \left(\frac{0.3215}{\sigma_{\max } / \sigma_{s}+0.0246}\right) \\
b_{1}=2.2498 \exp \left(\frac{-0.3215}{\sigma_{\max } / \sigma_{s}+0.0246}\right) \\
b_{2}=2.0764 \exp \left(\frac{-0.3215}{\sigma_{\max } / \sigma_{s}+0.0246}\right)
\end{array}\right.
$$

3.3. Application of the Crack Opening Stress Model. To verify the application of the new method, equations (7) and (8) are used to calculate the crack growth life under constant amplitude load. Firstly, the opening stress is calculated by equation (7); then the crack growth rate is calculated by equation (8), and finally the crack growth life is obtained by numerical integration in Python 3.8.

$$
\left\{\begin{array}{l}
d a / d N=C\left(\Delta K_{e f f}\right)^{m} \\
\Delta K_{e f f}=Y(a) \Delta \sigma_{e f f} \sqrt{\Pi a} \\
\sigma_{e f f}=\sigma_{\max }-\sigma_{o p}
\end{array}\right.
$$

Herein, the calculations are conducted under the same conditions as in [39]. The crack opening stress is compared with the result of Schijve formula [40]; and the calculation results are shown in Table 3.

Compared with the plastic zone size $3.2619 \mu m$, according to equation (2), the error of numerical result is $6.8 \%$, and, compared with the fatigue crack growth life 380192 cycles from [39], the error of the novel expression result is $5 \%$. Moreover, the crack opening stress calculated by Schijve formula is 0.45 , and the error of the novel expression result is $8.3 \%$. Therefore, equation (7) is credible within the scope of this work.

\section{Discussion}

The effect of compression load on reducing crack opening stress is shown in Figure 5 by stress ratio and maximum tensile load. Based on the relationship of quadratic trinomial between crack opening stress and stress ratio, equation (3) is obtained for calculating crack opening stress. The equation shows that the crack opening stress decreases with the increase of compression load (i.e., the increase of negative stress ratio), which is the same as the conclusion of previous research. Also equation (3) has a similar form to Newman's formula of crack opening stress.

The residual tensile stress, which formed in unloading stage of compressive load, promotes the crack opening. When the maximum tensile load is greater than $160 \mathrm{MPa}$ and the negative stress ratio is greater than -0.3 , the crack opens at the compressive unloading stage with the increase of compression load. Due to the plastic flow of material, the residual stress formed in the unloading stage of compressive
TABle 3: Verification of Equation 7.

\begin{tabular}{lccc}
\hline $\begin{array}{l}\text { Contrast } \\
\text { item }\end{array}$ & $\begin{array}{c}\text { Calculated } \\
\text { result }\end{array}$ & Cited result & $\begin{array}{c}\text { Relative error } \\
(\%)\end{array}$ \\
\hline$r_{p}$ & $3.0372 \mu m$ & $3.2619 \mu m$ & 6.8 \\
$N$ & 361182 cycles & $\begin{array}{c}380192 \\
\text { cycles }\end{array}$ & 5.0 \\
$\sigma_{o p} / \sigma_{\max }$ & 0.4125 & 0.450 & 8.3 \\
\hline
\end{tabular}

load promotes crack opening, which is similar to the previous conclusion. However, the residual tensile stress does not increase continuously with the increase of compression load. As shown in Figure 5, the crack opening stress curve tends to be horizontal with the increase of negative stress ratio. The reason is that the residual tensile stress is limited by the plastic deformation near crack tip in the stage of tensile loading, and the crack closure limits the plastic deformation under compressive loading. Therefore, the residual tensile stress in the unloading stage of compressive load makes the crack open, and the crack opening stress tends to be stable with the increase of compressive load.

The maximum applied tensile load determines whether the crack can open in the unloading stage of compressive load. The residual compressive stress caused by the unloading of tensile load makes the crack close ahead of time and delay the opening; namely, the amplitude of effective stress decreases. However, the residual tensile stress caused by unloading of compressive load slows down the effect of tensile load; that is, the effective stress amplitude increases. It can be seen from Figure 5 that the maximum tensile load is related to the crack opening behavior at the unloading stage of compressive load. When the maximum tensile load is greater than $160 \mathrm{MPa}$, the crack will open in the unloading stage of compressive load. Therefore, it is reasonable to put the maximum tensile load into equation (3).

As Table 3 shows, the results calculated by equation (7) with numerical model are credible. Equation (7) reflects the material characteristics and load characteristics; therefore the calculated crack growth life is accurate, as shown in Table 3. The simplified equation (7) is easier to apply than equations (4) and (3); also the determination coefficient and adjusted coefficient are greater than 0.95 , which means that the fitting effect is good. For the convenience of application, 0.3215 and 0.0246 in equation (8) can be further approximated to 0.3 and 0.03 , and the approximate formula for calculating crack growth life needs further verification.

\section{Conclusions}

This work aims at the estimation of crack opening stress under cyclic load with negative stress ratio. Based on the elastoplastic element analysis of CT specimen under cyclic load, the following conclusions can be drawn:

(1) A novel expression of crack opening stress is proposed, including the effect of compression load on crack opening stress.

(2) The novel expression reflects the material characteristics and load characteristics and can be used to 
calculate crack opening stress in the loading stage of tensile load and especially can be used to calculate crack opening stress in the unloading stage of compressive load.

(3) The results of comparative analysis show that the expression is accurate and easy to apply and also can be used to calculate crack opening stress and crack growth life under compression load.

\section{Data Availability}

The data used to support the findings of this study are included within the article.

\section{Conflicts of Interest}

The authors declare that they have no known competing financial interests or personal relationships that could have appeared to influence the work reported in this paper.

\section{Acknowledgments}

This research was supported by the National Defense Excellence Youth Science Foundation of China (2018-JCJQZQ-053).

\section{References}

[1] M. Khalil, "Prediction and correlation of the average crackopening stress with service load cycles," International Journal of Fatigue, vol. 25, no. 7, pp. 661-670, 2003.

[2] M. Khalil and T. H. Topper, "Prediction of crack opening stress levels for 1045 quenched and tempered steel under service loading spectra," Fatigue and Fracture of Engineering Materials and Structures, vol. 29, no. 1, pp. 3-10, 2006.

[3] H. Sayar, M. Azadi, and M. Alizadeh, "Detection of crack initiation and propagation in aluminum alloy under tensile loading, comparing signals acquired by acoustic emission and vibration sensors," Journal of Nondestructive Evaluation, vol. 38, no. 4, 2019.

[4] F. Berto, A. Campagnolo, and P. Lazzarin, "Fatigue strength of severely notched specimens made of ti-6al-4v under multiaxial loading," Fatigue and Fracture of Engineering Materials and Structures, vol. 38, no. 5, pp. 503-517, 2015.

[5] S. C. Wu, Y. X. Liu, C. H. Li, G. Z. Kang, and S. L. Liang, "On the fatigue performance and residual life of intercity railway axles with inside axle boxes," Engineering Fracture Mechanics, vol. 197, pp. 176-191, 2018.

[6] U. Zerbst, S. Beretta, G. Köhler et al., "Safe life and damage tolerance aspects of railway axles - a review," Engineering Fracture Mechanics, vol. 98, pp. 214-271, 2013.

[7] K. F. Walker, J. M. Lourenço, S. Sun, M. Brandt, and C. H. Wang, "Quantitative fractography and modelling of fatigue crack propagation in high strength AerMet100 steel repaired with a laser cladding process," International Journal of Fatigue, vol. 94, pp. 288-301, 2017.

[8] J. J. Chen, M. You, and Y. Huang, "A new expression for crack opening stress determined based on maximum crack opening displacement under tension-compression cyclic loading," Fatigue and Fracture of Engineering Materials and Structures, vol. 41, no. 1, pp. 29-40, 2018.
[9] J. Zhang, X. D. He, Y. Sha, and S. Y. Du, "The compressive stress effect on fatigue crack growth under tension-compression loading," International Journal of Fatigue, vol. 32, no. 2, pp. 361-367, 2010.

[10] R. Jones, "Fatigue crack growth and damage tolerance," $\mathrm{Fa}$ tigue and Fracture of Engineering Materials and Structures, vol. 37, no. 5, pp. 463-483, 2014.

[11] S. Beretta and D. Regazzi, "Probabilistic fatigue assessment for railway axles and derivation of a simple format for damage calculations," International Journal of Fatigue, vol. 86, pp. 13-23, 2016.

[12] Y. Xiong, J. Katsuta, K. Kawano, and T. Sakiyama, "Examination of fatigue crack driving force parameter," Fatigue and Fracture of Engineering Materials and Structures, vol. 31, no. 9, pp. 754-765, 2008.

[13] J. Yang, W. Zhang, and Y. Liu, "Existence and insufficiency of the crack closure for fatigue crack growth analysis," International Journal of Fatigue, vol. 62, pp. 144-153, 2014.

[14] S. C. Wu, C. H. Li, Y. Luo, H. O. Zhang, and G. Z. Kang, "A uniaxial tensile behavior based fatigue crack growth model," International Journal of Fatigue, vol. 131, p. 105324, Article ID 105324, 2020.

[15] P. Pokorný, T. Vojtek, M. Jambor, L. Náhlík, and P. Hutař, "Effect of underload cycles on oxide-induced crack closure development in cr-mo low-alloy steel," Materials, vol. 14, no. 10, p. 2530, 2021.

[16] S. Holdsworth, "Crack opening and closure stress ratios at elevated temperatures," Materials at High Temperatures, vol. 33, no. 2, pp. 115-119, 2016.

[17] S. C. Wu, Z. W. Xu, C. Yu, O. L. Kafka, and W. K. Liu, "A physically short fatigue crack growth approach based on low cycle fatigue properties," International Journal of Fatigue, vol. 103, pp. 185-195, 2017.

[18] J. Ramirez, G. P. Potirniche, N. Shaber et al., "The influence of plasticity-induced crack closure on creep-fatigue crack growth in two heat-resistant steels," International Journal of Fatigue, vol. 125, pp. 291-298, 2019.

[19] T. L. Panontin and S. D. Sheppard, Eds., Fatigue and Fracture Mechanics: 29th Volume, ASTM International, 100 Barr Harbor Drive, PO Box C700, West Conshohocken, PA, 1999.

[20] F. V. Antunes, R. Branco, J. D. Costa, and D. M. Rodrigues, "Plasticity induced crack closure in middle-crack tension specimen: numerical versus experimental," Fatigue and Fracture of Engineering Materials and Structures, vol. 33, no. 10, pp. 673-686, 2010.

[21] J. Newman, "An evaluation of plasticity-induced crack closure concept and measurement methods," in Advances in Fatigue Crack Closure Measurement and Analysis: Second Volume, ASTM International, 100 Barr Harbor Drive, R. C. McClung and J. C. Newman, Eds., p. 128, PO Box C700, West Conshohocken, PA, 1999.

[22] Z. Jing and X. R. Wu, "Wide-range weight functions and stress intensity factors for arbitrarily shaped crack geometries using complex taylor series expansion method," Engineering Fracture Mechanics, vol. 138, pp. 215-232, 2015.

[23] D. H. Tong and X. R. Wu, "Determination of crack surface displacements for cracks emanating from a circular hole using weight function method," Fatigue and Fracture of Engineering Materials and Structures, vol. 36, no. 4, pp. 340-348, 2013.

[24] J. P. Dempsey and Z. Mu, "Weight function for an edgecracked rectangular plate," Engineering Fracture Mechanics, vol. 132, pp. 93-103, 2014. 
[25] F. Silva, "The importance of compressive stresses on fatigue crack propagation rate," International Journal of Fatigue, vol. 27, no. 10-12, pp. 1441-1452, 2005.

[26] J. D. M. Costa and J. A. M. Ferreira, "Effect of stress ratio and specimen thickness on fatigue crack growth of ck45 steel," Theoretical and Applied Fracture Mechanics, vol. 30, no. 1, pp. 65-73, 1998.

[27] M.-L. Zhu, F.-Z. Xuan, and S.-T. Tu, "Effect of load ratio on fatigue crack growth in the near-threshold regime: a literature review, and a combined crack closure and driving force approach," Engineering Fracture Mechanics, vol. 141, pp. 57-77, 2015.

[28] K. R. Venkatesan and Y. Liu, "Subcycle fatigue crack growth formulation under positive and negative stress ratios," Engineering Fracture Mechanics, vol. 189, pp. 390-404, 2018.

[29] J. Liu, P. Du, X. Liu, and Q. Du, "Modeling of fatigue crack growth closure considering the integrative effect of cyclic stress ratio, specimen thickness and Poisson's ratio," Chinese Journal of Mechanical Engineering, vol. 25, no. 4, pp. 816-825, 2012.

[30] A. J. McEvily, "Recent advances in fatigue crack growth," Key Engineering Materials, vol. 510-511, pp. 15-21, 2012.

[31] D. M. Rodrigues and F. V. Antunes, "Finite element simulation of plasticity induced crack closure with different material constitutive models," Engineering Fracture Mechanics, vol. 76, no. 9, pp. 1215-1230, 2009.

[32] R. Chen, M.-L. Zhu, F.-Z. Xuan, S.-C. Wu, and Y.-N. Fu, "Near-tip strain evolution and crack closure of growing fatigue crack under a single tensile overload," International Journal of Fatigue, vol. 134, p. 105478, Article ID 105478, 2020.

[33] L. P. Borrego, J. D. Costa, and J. A. M. Ferreira, "Crack propagation of 7050 aluminum alloy under constant amplitude loading and peak overloads," Procedia Engineering, vol. 114, pp. 613-620, 2015.

[34] K. Masuda, S. Ishihara, Y. Sugai, and A. J. McEvily, "Experimental and numerical simulation study of plasticity-induced and roughness-induced fatigue crack closure," Advanced Materials Research, vol. 891-892, pp. 307-312, 2014.

[35] L. P. Borrego, F. V. Antunes, J. D. Costa, and J. M. Ferreira, "Numerical simulation of plasticity induced crack closure under overloads and high-low blocks," Engineering Fracture Mechanics, vol. 95, pp. 57-71, 2012.

[36] D.-H. Tong and X.-R. Wu, "Analysis of crack opening stresses for center- and edge-crack tension specimens," Chinese Journal of Aeronautics, vol. 27, no. 2, pp. 291-298, 2014.

[37] W. Riddell, R. Piascik, M. Sutton, W. Zhao, S. McNeill, and J. Helm, "Determining fatigue crack opening loads from nearcrack-tip displacement measurements," in Advances in Fatigue Crack Closure Measurement and Analysis: Second Volume, ASTM International, 100 Barr Harbor Drive, R. C. McClung and J. C. Newman, Eds., p. 157, PO Box C700, West Conshohocken, PA, 1999.

[38] R. C. McClung and J. C. Newman, Eds., Advances in Fatigue Crack Closure Measurement and Analysis: Second Volume, ASTM International, 100 Barr Harbor Drive, PO Box C700, West Conshohocken, PA, 1999.

[39] W. Tu, J. Yue, H. Xie, and W. Tang, "Fatigue crack propagation behavior of high-strength steel under variable amplitude loading," Engineering Fracture Mechanics, vol. 247, p. 107642, Article ID 107642, 2021.

[40] W. Yisheng and J. Schijve, "Fatigue crack closure measurements on 2024-t3 sheet specimens," Fatigue and Fracture of Engineering Materials and Structures, vol. 18, no. 9, pp. 917-921, 1995. 